\title{
COVID-19 Treatment: The Race Against Time
}

\author{
Mohamad Aljofan ${ }^{1 *}$, Abduzhappar Gaipov ${ }^{2}$
}

\begin{abstract}
${ }^{1}$ Department of Biomedical Sciences, Nazarbayev University School of Medicine, Nur-Sultan, KAZAKHSTAN
${ }^{2}$ Department of Clinical Sciences, Nazarbayev University School of Medicine, Nur-Sultan, KAZAKHSTAN

${ }^{\star}$ Corresponding Author: Mohamad.aljofan@nu.edu.kz
\end{abstract}

Citation: Aljofan M, Gaipov A. COVID-19 Treatment: The Race Against Time. Electron J Gen Med. 2020;17(6):em227. https://doi.org/10.29333/ejgm/7890

ARTICLE INFO
Received: 4 Mar. 2020
Accepted: 5 Mar. 2020

\begin{abstract}
The new outbreak of the novel coronavirus infection emerged in Wuhan- China in late 2019, by the end of Mar 2020, it has spread in more than 178 countries and territories. There is no vaccine or antiviral treatment for COVID-19. Currently, there are several drugs and vaccines being tested for their potential activity against the disease. In this review, we briefly discuss some of the investigational drugs and vaccines being tested against COVID-19 as well as their potential drawbacks.
\end{abstract}

Keywords: COVID-19, treatment, clinical trials, Chloroquine, Lopinavir-ritonavir, Remdesivir, Tocilizumab, Camostat mesilate

\section{INTRODUCTION}

The world is carrying two concurrent wars against the newly emerged coronavirus disease (COVID-19), which was first reported in the Chinese city of Wuhan late last year. On the one hand, the world is trying to slow down or stop the spread of the disease, and on the other hand, desperately trying to find effective treatments. There is an increasing number of clinical trials for testing potential treatment or vaccine for COVID-19. Currently, there are 60 active and recruiting clinical trials (as of $31^{\text {st }}$ of Mar 2020; refer to ClinicalTrials.org). The majority of the trials aim to repurpose commonly used medications including, antimalaria, anti-influenza, and anti-HIV combinations as well as other commonly available drugs. In this review we briefly discuss some of the investigational compounds that showed promising results based on their compassionate use and are currently in clinical trials as potential antivirals against COVID19.

\section{Chloroquine / Hydroxychloroquine}

Chloroquine/hydroxychloroquine is one of the most promising compounds that has gained international attention for its potential activity against COVID-19 (1). Despite the lack of conclusive evidence of their effectiveness against COVID-19, the FDA issued an emergency authorisation for their use against COVID-19. While the drug was shown to inhibit the virus in vitro, the required dose in human is thought to be quite high and could lead to severe toxicity. Also, the use of hydroxychloroquine is associated with various side effects and could, although rarely, cause cardiomyopathy, that can only be reversed by immediate discontinuation, thus reduces its potential usefulness in some patients (2).

\section{Lopinavir-Ritonavir}

Lopinavir-ritonavir is a combination of fixed doses of protease inhibitors used for the treatment of HIV (3). The use of this combination was shown to have potent antiviral activity against the severe acute respiratory syndrome (SARS) virus (4). The treatment was also shown to be effective as a post exposure prophylaxis against other viral diseases including middle east respiratory syndrome (MERS) (5). However, the results of a recent trail of the combination (lopinavir-ritonavir) in 199 adults with laboratory confirmed COVID-19 reported no benefits observed with the combination compared to standard care (5).

\section{Remdesivir}

Remdesivir is a monophosphoramidate prodrug of an adenosine analogue (6). It is an investigational broad-spectrum antiviral drug with in vitro activity against multiple RNA viruses, including Ebola and CoV (7). Results from animal testing reported promising results in inhibiting other coronavirus infections including severe acute respiratory syndrome (SARS) and middle east respiratory syndrome (MERS) (8). Despite the lack of solid clinical trials, the drug was administered to several patients with COVID-19 infections (9). Currently, there are several ongoing clinical trials to investigate the potential antiviral efficacy remdesivir against COVID-19 in China and the US (10). However, the drug failed its previous attempt in prolonging Ebola patients in the recent African outbreak of Ebola virus (11).

\section{Tocilizumab}

Tocilizumab is a humanized antibody of the IgG1 subclass that inhibits the inflammatory cytokine, interlukine-6 (IL-6) receptor, leading to an immunosuppression (12). The drug is approved for the treatment of mild to severe adult rheumatoid 
arthritis, giant cell arteritis, and juvenile idiopathic arthritis (13). The drug is being tested in patients with potential risk of cytokine storm driven hyperinflammation (also known as cytokine release syndrome) a systemic inflammatory response that can be trigged by infections including COVID-19 (14). Recent findings from China suggested that COVID-19 mortality might be due to virally driven hyperinflammation. Although, immunosuppressants are not recommended in viral infections and their use may exacerbate COVID-19, in the case of cytokine storm, the drug is likely to be beneficial (15). Currently, the drug has been approved in China for COVID-19 patients with pneumonia and elevated IL-6 (16). Therefore, it is recommended that severe COVID-19 patients should be screened for potential hyperinflammation and to identify those patients that may benefit from the use of such medications.

\section{Camostat Mesilate}

Camostat mesilate is a protease inhibitor that is approved for the treatment of pancreatic inflammation in Japan (17). COVID-19 entry into the cell depends on binding of the viral spike proteins (S) to cellular receptors, angiotensin converting enzyme 2 (ACE2) and on S protein priming by host proteases (TMPRSS2) (18). Camostat mesilate has recently been shown to block COVID-19 entry into the cell by inhibiting the cellular host TMPRSS2 (19). While this explains the potential mechanism of viral entry, however, more testing is required before it can possible be labelled as an effective therapy for the treatment of COVI-19.

There are no effective treatment or vaccine for the newly emerged COVID-19 virus. Hence, there is an urgent need for safe and effective treatment for this devastating virus. While most of these drugs are presently used for other viral infections, and some were shown to be effective in a small number of patients with COVID-19 (based on the results of small trials and compassionate use), we believe it is still premature to assume the efficacy of any of these drugs against COVID-19. The current brief review summarises some of the potential therapeutics currently being investigated in human trials. It will serve as a basis for future antiviral research for the treatment of COVID-19 as well as other related viruses.

\section{LIMITATIONS}

The current manuscript is a brief review of the therapeutics being tested in clinical trials based on the details provided by ClinicalTrials.org. Therefore, it cannot be viewed as a comprehensive review of the literature for these drugs. Also, the drugs discussed in the manuscript still under investigation, and thus the manuscript should not be used as a basis for therapeutic uses for the treatment of COVID-19.

\section{REFERENCES}

1. Aljofan M, Gaipov A. Chloroquine and COVID-19: A Light at the End of the Tunnel, or is it Another Train?. Electron J Gen Med. 2020;17(4):em207. https://doi.org/10.29333/ejgm/ 7863

2. Zhao H, Wald J, Palmer M, Han Y. Hydroxychloroquineinduced cardiomyopathy and heart failure in twins. Journal of thoracic disease. 2018;10(1):E70. https://doi.org/10. 21037/JTD.2017.12.66 PMID:29600108 PMCID:PMC5863196
3. Zeldin RK, Petruschke RA. Pharmacological and therapeutic properties of ritonavir-boosted protease inhibitor therapy in HIV-infected patients. Journal of antimicrobial chemotherapy. 2004;53(1):4-9. https://doi.org/10.1093/jac/dkh029 PMID:14657084

4. Chu C, Cheng V, Hung I, Wong M, Chan K, Chan K, et al. Role of lopinavir/ritonavir in the treatment of SARS: initial virological and clinical findings. Thorax. 2004;59(3):252-6. https://doi.org/10.1136/thorax.2003.012658 PMID:14985565 PMCID:PMC1746980

5. Park S, Lee J, Son J, Ko J, Peck K, Jung Y, et al. Postexposure prophylaxis for Middle East respiratory syndrome in healthcare workers. Journal of Hospital Infection. 2019;101(1):42-6. https://doi.org/10.1016/j.jhin.2018.09. 005 PMID:30240813 PMCID:PMC7114948

6. De Clercq E. New Nucleoside Analogues for the Treatment of Hemorrhagic Fever Virus Infections. Chemistry-An Asian Journal. 2019;14(22):3962-8. https://doi.org/10.1002/asia. 201900841 PMID:31389664

7. Tchesnokov EP, Feng JY, Porter DP, Götte M. Mechanism of inhibition of Ebola virus RNA-dependent RNA polymerase by remdesivir. Viruses. 2019;11(4):326. https://doi.org/ 10.3390/v11040326 PMID:30987343 PMCID:PMC6520719

8. Yethindra V. Role of GS-5734 (Remdesivir) in inhibiting SARS-CoV and MERS-CoV: The expected role of GS-5734 (Remdesivir) in COVID-19 (2019-nCoV)-VYTR hypothesis. International Journal of Research in Pharmaceutical Sciences. 2020;11(SPL1):1-6. https://doi.org/10.26452/ ijrps.v11iSPL1.1973

9. NIH clinical trial of remdesivir to treat COVID-19 begins. U.S. https://www.nih.gov/news-events/news-releases/nih-

clinical-trial-remdesivir-treat-covid-19-begins [press release]. U.S. Department of Health and Human ServicesFebruary 25, 2020.

10. Clinical trials on Remdesivir and COVID-19 [cited 2020 April 2]. Available at: https://clinicaltrials.gov/ct2/results? cond=COVID-19

11. Mulangu S, Dodd LE, Davey Jr RT, Tshiani Mbaya O, Proschan M, Mukadi D, et al. A randomized, controlled trial of Ebola virus disease therapeutics. New England Journal of Medicine. 2019;381(24):2293-303. https://doi.org/ 10.1056/NEJMoa1910993 PMID:31774950

12. Sebba A. Tocilizumab: the first interleukin-6-receptor inhibitor. American Journal of Health-System Pharmacy. 2008;65(15):1413-8. https://doi.org/10.2146/ajhp070449 PMID:18653811

13. Maini R, Taylor P, Szechinski J, Pavelka K, Bröll J, Balint G, et al. Double - blind randomized controlled clinical trial of the interleukin - 6 receptor antagonist, tocilizumab, in European patients with rheumatoid arthritis who had an incomplete response to methotrexate. Arthritis \& Rheumatism. 2006;54(9):2817-29. https://doi.org/10.1002/ art.22033 PMID:16947782

14. Shimabukuro-Vornhagen A, Gödel $P$, Subklewe $M$, Stemmler HJ, Schlößer HA, Schlaak M, et al. Cytokine release syndrome. Journal for immunotherapy of cancer. 2018;6(1):56. https://doi.org/10.1186/s40425-018-0343-9 PMID:29907163 PMCID:PMC6003181

15. Russell CD, Millar JE, Baillie JK. Clinical evidence does not support corticosteroid treatment for 2019-nCoV lung injury. The Lancet. 2020;395(10223):473-5. https://doi.org/10.1016/S0140-6736(20)30317-2 
16. Chinese Clinical Trial Registry. A multicenter, randomized controlled trial for the efficacy and safety of tocilizumab in the treatment of new coronavirus pneumonia (COVID-19). 2020 [Available at: http://www.chictr.org.cn/ showprojen.aspx?proj=49409

17. Yamauchi J-i, Takeda K, Shibuya K, Sunamura M, Matsuno S. Continuous Regional Application of Protease Inhibitor in the Treatment of Acute Pancreatitis. Pancreatology. 2001;1(6):662-7. https://doi.org/10.1159/000055878 PMID:12120251
18. Li W, Moore MJ, Vasilieva N, Sui J, Wong SK, Berne MA, et al. Angiotensin-converting enzyme 2 is a functional receptor for the SARS coronavirus. Nature. 2003;426(6965):450-4. https://doi.org/10.1038/nature02145 PMID:14647384 PMCID:PMC7095016

19. Hoffmann M, Kleine-Weber H, Schroeder S, Krüger N, et al. SARS-CoV-2 cell entry depends on ACE2 and TMPRSS2 and is blocked by a clinically proven protease inhibitor. Cell. 2020. https://doi.org/10.1016/j.cell.2020.02.052 PMID:32142651 PMCID:PMC7102627 